\title{
Relation between exposure to fluoride and bronchial responsiveness in aluminium potroom workers with work-related asthma-like
} symptoms

Vidar Søyseth, Johny Kongerud, Jan Ekstrand, Jacob Boe

\begin{abstract}
Background - The relation between plasma fluoride levels and bronchial responsiveness was investigated in a longitudinal study in aluminium potroom workers who reported work-related asthmatic symptoms.

Methods - From a cross-sectional respiratory survey, 26 men who reported work-related asthmatic symptoms on a validated questionnaire were selected for repeated measurements of bronchial responsiveness to methacholine. Regular analyses of plasma fluoride levels were performed. Exposure to fluoride and total particulates was assessed from routine surveillance of the workplace. Bronchial responsiveness was expressed as the doseresponse slope of the line through the origin and last data point.

Results - A positive association was found between bronchial responsiveness and plasma fluoride levels, such that an increase in the plasma fluoride level of $10 \mathrm{ng} /$ $\mathrm{ml}$ was associated with an increase in the dose-response slope by a factor of $1 \cdot 11$ (95\% confidence interval 1.05 to $1 \cdot 17)$. Plasma fluoride levels were associated with the total atmospheric fluoride concentration in $\mathrm{mg} / \mathrm{m}^{3}(\beta=28 \cdot 1)$, but not with total particulates in the environment.

Conclusions - Bronchial responsiveness in aluminium potroom workers reporting work-related asthmatic symptoms appears to be related to plasma levels of fluoride. The underlying mechanism is, however, unknown.
\end{abstract}

(Thorax 1994;49:984-989)

Department of
Thoracic Medicine, Rikshospitalet, University of Oslo, Norway

V Søyseth

J Kongerud

J Boe

Department of Dental Toxicology, Karolinska Institute, Huddinge, Sweden

J Ekstrand

Reprint requests to: Dr V Seyseth.

Received 14 December 1993 Returned to authors

1 February 1994

Revised version received

24 February 1994

Accepted for publication

1 July 1994 patients who develop late asthmatic reactions after specific provocation, this reaction is accompanied by an increase in bronchial responsiveness. ${ }^{67}$ The level of bronchial responsiveness may therefore be an indicator of

Asthma and asthma-like symptoms are asspecific bronchoconstrictive agents methacholine, ${ }^{1}$ although the degree of bror jects with asthma-like symptoms changes with time ${ }^{23}$ and occupational asthma with bronchial responsiveness in the normal range has also the degree of airway inflammation. ${ }^{8}$

Aluminium potroom asthma was first described 60 years ago. ${ }^{9}$ Kongerud and Samuelsen found that the incidence of work-related asthma-like symptoms in new employees who were asymptomatic at the time of employment was positively associated with exposure to fluoride. ${ }^{10}$ It is not clear whether this syndrome is merely provoked by irritants in subjects with pre-existing bronchial hyperresponsiveness or is induced by an agent in the environment that increases the bronchial responsiveness itself. ${ }^{11}$ Two reports have suggested that bronchial resposiveness decreases when exposure to the irritant ceases. $^{1213}$ The relation between occupational exposure and bronchial responsiveness in aluminium potroom workers reporting work-related asthmatic symptoms remains, however, to be clarified. ${ }^{11}$

The aim of this study was to investigate the relation between bronchial responsiveness and plasma fluoride levels and exposure to total fluoride and total particulates in the environment. We also wished to study the association between plasma fluoride levels and workplace exposure to fluoride and particulates.

\section{Methods}

In 1986 a cross-sectional survey of aluminium potroom workers (response rate $98 \%$ ) was carried out at an aluminium plant in western Norway (Hydro Aluminium Årdal). Respiratory symptoms were recorded on a questionnaire $^{14}$ and spirometric tests were performed with a dry bellow spirometer (Jones Pulmonaire, Jones Medical Instruments Company, Oak Brook, Illinois, USA). At the planning stage of this study a protocol for selection of workers from this cross-sectional survey to a longitudinal study of bronchial responsiveness was also carried out. The inclusion criteria were: (1) men with occasional wheezing and dyspnoea in connection with potroom atmosphere exposure lasting less than two hours; (2) no complaints during vacations (workrelated asthmatic symptoms); (3) no hospital admissions because of asthma; (4) no asthma before entering potroom work (this information was obtained from a validated questionnaire ${ }^{14}$ ); (5) lung function $\left(\mathrm{FEV}_{1}\right)>80 \%$ of predicted during symptom free periods. ${ }^{15}$ We chose not to include women because only about $10 \%$ of the workforce were women. Of 40 subjects 
Table 1 Geometric mean of exposure to total fluoride and particulates $\left(\mathrm{mg} / \mathrm{m}^{3}\right)$ in the 26 subjects who participated in the study

\begin{tabular}{|c|c|c|c|c|c|c|}
\hline \multirow[b]{2}{*}{ Year } & \multicolumn{2}{|l|}{ Prebake 1} & \multicolumn{2}{|l|}{ Prebake 2} & \multicolumn{2}{|l|}{ Soderberg } \\
\hline & Total fluoride & Total particulates & Total fluoride & Total particulates & Total fluoride & Total particulates \\
\hline $\begin{array}{l}1986 \\
1987 \\
1988 \\
1989\end{array}$ & $\begin{array}{l}0.94 \\
0.83 \\
0.71 \\
0.30\end{array}$ & $\begin{array}{l}3.58 \\
4.06 \\
3.99 \\
1.37\end{array}$ & $\begin{array}{l}0.66 \\
0.34 \\
0.33 \\
0.16\end{array}$ & $\begin{array}{l}3.24 \\
1.58 \\
1.16 \\
0.47\end{array}$ & $\begin{array}{l}0.57 \\
0.28 \\
0.30 \\
0.17\end{array}$ & $\begin{array}{l}2.97 \\
1.90 \\
2.57 \\
0.88\end{array}$ \\
\hline
\end{tabular}

with work-related asthmatic symptoms 14 were excluded: five were women, one was more than 60 years of age, seven had an $\mathrm{FEV}_{1}<80 \%$ of the predicted value, and one did not wish to participate. Consequently, 26 subjects gave their informed consent to participate in the study.

Their median age was 35.5 years (range 25-2-56.7) and median $\mathrm{FEV}_{1}$ as a percentage of predicted was $94 \%$ (range $80-105 \%$ ). Ten subjects used $\beta_{2}$ agonists (four regularly, six intermittently), whereas the remainder did not take any medication. There were 17 current smokers, four former smokers, and five never smokers. A skin prick test to five common aeroallergens was also performed; the result was regarded as positive if the weal from any of the allergens was larger than the histamine reference. A positive reaction was found in four subjects. Their mean duration of employment was $12 \cdot 5$ years.

Methacholine challenge testing was performed as suggested by Cockcroft et al. ${ }^{16} \mathrm{We}$ used the same spirometer as in the cross-sectional study in 1986. The same nebuliser was used throughout the study, calibrated to give an output of $0.13 \mathrm{ml} / \mathrm{min}$. Aerosols were inhaled by tidal breathing for two minutes by doubling the concentration of methacholine at five minute intervals starting at $0 \cdot 125 \mathrm{mg} / \mathrm{ml}$. The test was discontinued when the $\mathrm{FEV}_{1}$ had fallen by more than $20 \%$ of the pretest value or when a methacholine concentration of $32.0 \mathrm{mg} / \mathrm{ml}$ was reached. Details of the procedure are described elsewhere. ${ }^{13}$

Venous blood was taken immediately before the methacholine challenge. Plasma was separated and immediately frozen and stored at $-70^{\circ} \mathrm{C}$ until it was analysed for fluoride by an ion sensitive method. ${ }^{17}$

The smelter has two prebake departments and one Søderberg department. ${ }^{11}$ Clean alumina is used in the Søderberg pots, whereas the alumina in the prebake pots is recycled from the dry scrubbers in the plant. The alumina in the prebake pots is thus contaminated with emission gases from the pots. The work is divided into different job categories and the workers were classified accordingly. ${ }^{18}$ Results obtained from annual routine surveillance by personal sampling were available for calculation of exposure to total fluoride and particulates in each job category - that is, information on environmental exposure was collected from subjects randomly selected from the total population of potroom workers. The geometric mean of the measurements was used as an estimate of the atmospheric exposure. These job-specific estimates of exposure were used as environmental estimates of exposure in each worker who was followed. Sulphur dioxide is also emitted from the pots, but personal samplers of this contaminant were not available. The annual mean exposure to total fluoride and total particulates in each department during follow up is shown in table 1. During this period there was a decline in the atmospheric concentration of total fluoride and particulates. This improvement in exposure was due to efforts made to improve the process such as delegation of more responsibility, better education of the pot operators, and better computerised control of the pots.

The subjects were examined at regular intervals (every third month) over a period of two years between December 1986 and January 1989. The mean number of tests was 6.5 and the mean observation time was 20.8 months. Only five of the 26 were challenged on nine occasions (maximum number); the subjects were allowed to withdraw from the study at any time without reporting the reason for their decision. The reason for withdrawal was unknown and probably not selective. All the tests were performed between midday and 13.30 hours, and the subjects had been working for 5-6 hours before each test. In the event of upper respiratory infection during the six weeks before the tests, these were postponed for six weeks. The subjects had not taken $\beta_{2}$ agonists for six hours before each test.

\section{DATA ANALYSIS}

Bronchial responsiveness was expressed as the slope of the line through the origin and the last data point as proposed by O'Connor and coworkers, ${ }^{19}$ and was calculated from the following expression:

$$
\underset{\left(\mathrm{FEV}_{1, \text { pretest }}-\mathrm{FEV}_{1, \text { posttes }}\right)}{\left.\left(\mathrm{FEV}_{1, \text { pretest }}\right)\right]} \times 100 /\left[\left(\mathrm{M}_{\mathrm{c}}\right)\right.
$$

where $F E V_{1 \text {,pretest }}$ is the highest $F E V_{1}$ before the challenge, $\mathrm{FEV}_{1 \text {,posttest }}$ corresponds to the $\mathrm{FEV}_{1}$ at the last concentration of methacholine, and $M_{c}$ is the highest concentration of methacholine used.

As the dose-response slope is highly skewed to the right it was log transformed using natural logarithms. ${ }^{19}$ To eliminate log transformation of negative values and values close to zero the dose-response slope was set at $5 \% / 32.0 \mathrm{mg} /$ $\mathrm{ml}(=0.156 \mathrm{ml} \% / \mathrm{mg})$ if a subject displayed a decrease in $\mathrm{FEV}_{1}$ of less than $5 \%$ at the highest concentration of methacholine $(32 \cdot 0 \mathrm{mg} / \mathrm{ml})$. This cutoff point was chosen because the reproducibility criterion for $\mathrm{FEV}_{1}$ was $5 \%$. This procedure caused censoring of 22 of the 169 tests at dose-response slope $=0 \cdot 156 \mathrm{ml} \% / \mathrm{mg}$. 


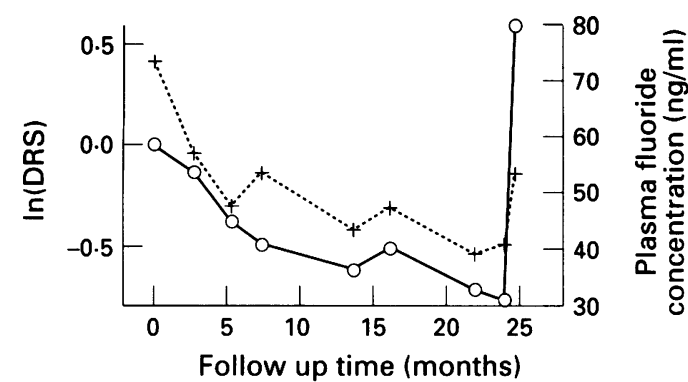

Figure 1 Mean plasma fluoride concentration (.....) and mean $\ln (D R S)$ (dose-response slope, $\longrightarrow$ ) during follow $u p$.

The relation between bronchial responsiveness and plasma fluoride levels was estimated in two different ways. Individual slopes of bronchial responsiveness and plasma levels of fluoride were calculated using least squares regression, and generalised estimation equations (GEE) were used to estimate the overall relation between the outcome and covariates with allowance for inclusion of covariates (including time-dependent covariates) in the model. This methodology has been developed by Zeger and Liang ${ }^{20}$ and is based on a statistical theory referred to as quasilikelihood. This approach permits different correlation structures to be considered as well as relaxing the unbalanced design requirement. Furthermore, it allows for different time spacing between subjects and is highly resistant to deviation from normality ${ }^{20}$ so that any truncation due to the censoring of subjects who did not react to methacholine should not cause any computational problems. The analyses were performed using the GEE procedure of the SPIDA statistical package. ${ }^{21}$ The natural logarithm of the dose-response slope ( $\ln (\mathrm{DRS})$ ) was entered as a continuous estimate of bronchial responsiveness as the dependent variable. The time-dependent characteristics were included as covariates varying with time throughout the study. A constant correlation between tests was assumed.

In a previous study we found that lung function was associated with bronchial responsiveness $^{22}$ so standardised $\mathrm{FEV}_{1}$ values were used to adjust for changes in lung function during follow up. ${ }^{23}$ As the subjects were selected with the presence of respiratory symptoms, a "regression toward the mean" was to be expected. ${ }^{24}$ Consequently, follow up time (months) was included as a covariate. Information about technology (prebake/Søderberg) was used as an indicator of scrubbed alumina exposure. As total levels of fluoride and particulates were estimated from the routine surveillance of the potroom atmosphere, these covariates could be regarded as indicators of the background occupational exposure. On the other hand, plasma fluoride levels increase twofold from preshift to postshift values. ${ }^{25}$ Hence, the plasma levels of fluoride should be regarded as an indicator of the occupational exposure on the day of bronchial challenge.

Multivariate model building was performed in analogy to a strategy for variable selection for logistic regression suggested by Hosmer and Lemeshow. ${ }^{26}$ The first step in these analyses was to investigate the univariate association between $\ln (\mathrm{DRS})$ and the covariates separately using the GEE method. The initial multivariate model then included those covariates that were associated with $\ln (\mathrm{DRS})$ at a significance level of $p \leqslant 0.25$ along with variables of biological importance. Finally, the model was reduced by deleting the variables which did not contribute significantly to the model $(\mathrm{p}<0.05)$ provided that the deletion did not markedly change the estimates of the remaining coefficients compared with the full model. ${ }^{26}$ The results of the final model were given as the ratio $\mathrm{DRS}_{x+\Delta x}$ $\mathrm{DRS}_{x}$ - that is, the relative change in the doseresponse slope by increasing the covariate by $\Delta x$ (Appendix).

\section{Results}

The mean bronchial responsiveness (adjusted for bronchial responsiveness at inclusion) and the mean concentration of plasma fluoride shown in fig 1 indicate that bronchial responsiveness and plasma fluoride concentrations were positively correlated. A decrease in bronchial responsiveness during the follow up period was also seen (the increase in bronchial responsiveness and plasma fluoride concentration at the endpoint is mainly due to the small number of subjects). In fig 2 the individual slopes of $\ln (\mathrm{DRS}) v$ plasma fluoride levels are plotted against the number of follow up visits. The mean slope obtained from the least squares estimates was $1.30 \times 10^{-2}(95 \%$ confidence interval $0.98 \times 10^{-2}$ to $1.62 \times 10^{-2}$ ).

The results from the univariate analyses indicated that the following covariates reached a sufficiently high level of significance to be included in the initial multivariate model: technology (prebake $v$ Søderberg), plasma fluoride level, follow up time, total particulates, and smoking. As the aim of the study was to investigate the relation between bronchial responsiveness and occupational exposure, total fluoride exposure was also kept in the initial multivariate model even though $\mathrm{p}>0 \cdot 25$. The univariate association between $\ln (\mathrm{DRS})$ and plasma fluoride levels using the GEE method was $1.47 \times 10^{-2}(95 \%$ confidence interval $0.95 \times 10^{-2}$ to $2.00 \times 10^{-2}$ ).

Smoking habit was dropped from the model according to the criteria for model reduction.

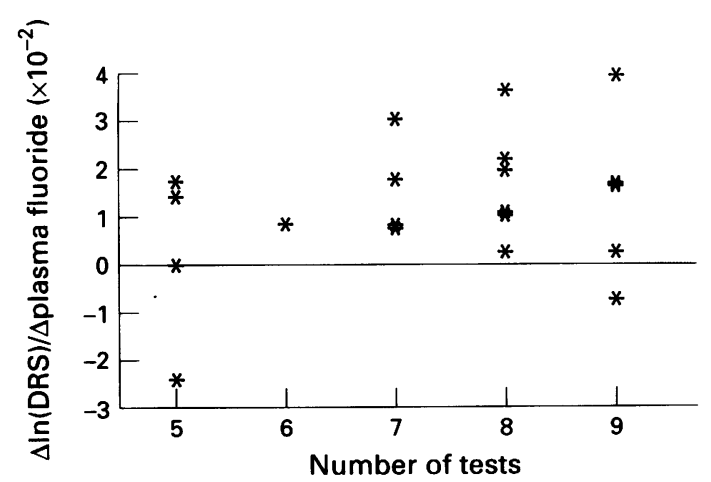

Figure 2 Individual slopes of the relation between In (DRS) (dose-response slope) and plasma fluoride concentration obtained by least squares regression. 
Table 2 Relative change in $D R S\left(D R S_{x+\Delta x} / D R S_{x}\right)$ by increasing the covariate by an amount of $\Delta x$ obtained from the final multivariate model using the GEE procedure for repeated measurements, grouped by subject

\begin{tabular}{llll}
\hline Independent variable & $\Delta x$ & $D R S_{x+\Delta x} / D R S_{x}$ & $95 \% C I$ \\
\hline Technology & & & \\
$\quad$ Prebake $v$ Søderberg & - & 0.39 & 0.19 to 0.76 \\
Plasma fluoride (ng/ml) & 10 & 1.11 & 1.05 to 1.17 \\
Follow up time (months) & 6 & 0.89 & 0.83 to 0.96 \\
Total particulates $\left(\mathrm{mg} / \mathrm{m}^{3}\right)$ & 1.0 & 0.92 & 0.87 to 0.98 \\
Total fluoride $\left(\mathrm{mg} / \mathrm{m}^{3}\right)$ & 0.5 & 1.25 & 0.80 to 1.94 \\
\hline
\end{tabular}

DRS $=$ dose-response slope.

Table 3 Regression of plasma fluoride concentration ( $\mathrm{ng} / \mathrm{ml}$ ) as the dependent variable using the GEE procedure for repeated measurements grouped by subject

\begin{tabular}{lccl}
\hline Independent variable & $\beta$ & $S E$ & $p$ \\
\hline Technology & & & \\
Prebake $v$ Søderberg & $-10 \cdot 4$ & $7 \cdot 3$ & $0 \cdot 16$ \\
Total particulates $\left(\mathrm{mg} / \mathrm{m}^{3}\right)$ & $-3 \cdot 3$ & $2 \cdot 3$ & $0 \cdot 15$ \\
Total fluoride $\left(\mathrm{mg} / \mathrm{m}^{3}\right)$ & $28 \cdot 1$ & $9 \cdot 4$ & $0 \cdot 003$ \\
\hline
\end{tabular}

Apart from total fluoride exposure, the coefficients between bronchial responsiveness and the other covariates were significant $(p<0.01)$. The removal of total fluoride exposure from the model caused the distortion of the coefficient between bronchial responsiveness and total particulate exposure. As a result, total fluoride exposure was kept in the model even though its association with bronchial responsiveness was not significant. Due to a high number of dropouts the model was fitted to the first five follow up visits that is, complete follow up of $85 \%$ of the subjects. The analysis of this subset caused only minor changes to the relation between $\ln$ (DRS) and plasma fluoride concentration) $\beta_{\text {all }}=1.02 \times 10^{-2} v \beta_{\text {subset }}=0.92 \times 10^{-2}$ ) and the association between bronchial responsiveness and plasma fluoride concentration remained significant $(\mathrm{p}<0.005)$.

The results of the final mode are given in table 2. An increase in plasma fluoride levels of $10 \mathrm{ng} / \mathrm{ml}$ was associated with a relative increase in the dose-response slope of $1 \cdot 11$ $(p<0.001)$ - that is, an increase of plasma fluoride of $66 \mathrm{ng} / \mathrm{ml}$ should be associated with a doubling of the dose-response slope (fig 3). Similarly, the relative decrease in the doseresponse slope per month during the follow up was 0.98 , equivalent to 0.80 per year $(\mathrm{p}<0.005)$. A decrease of the relative doseresponse slope per $1.0 \mathrm{mg} / \mathrm{m}^{3}$ increase in total particulates of $0.92(p<0.01)$ was also found. Finally, an increase in total fluoride exposure of $0.5 \mathrm{mg} / \mathrm{m}^{3}$ was associated with a relative

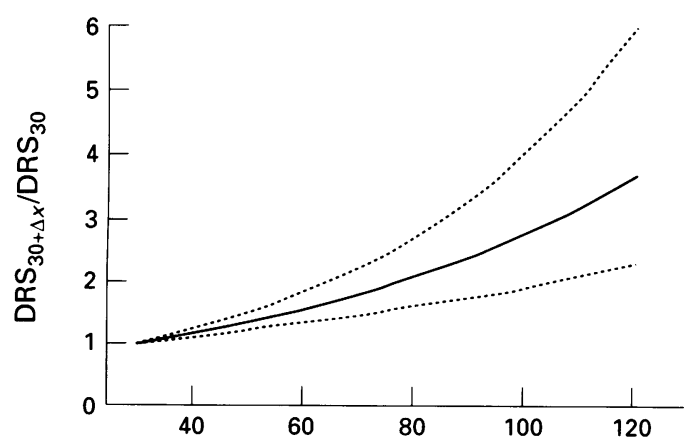

Plasma fluoride concentration $(\mathrm{ng} / \mathrm{ml}): 30+\Delta x$

Figure 3 The estimated ratio $D R S_{\mathrm{x}+\Delta \mathrm{x}} / D R S_{\mathrm{x}}$ as a function of plasma fluoride concentration. Broken lines $=$ 95\% confidence intervals. increase in the dose-response slope of $1 \cdot 25$, although this was not significant. However, total particulate and total fluoride exposures were highly correlated $(\beta=3 \cdot 66, \mathrm{SE}=0 \cdot 27$, $\mathrm{p}<0.001)$, and the relation between bronchial responsiveness and exposure to total particulates and total fluoride was dependent on whether or not both were kept in the model, as outlined above.

A decrease in exposure to total fluoride and total particulates during the follow up period was seen (table 1). The relation between plasma levels of fluoride and total fluoride exposure was significant $(\beta=28 \cdot 1, p<0 \cdot 005)$, whereas no association between plasma fluoride levels and exposure to total particulates occurred (table 3). There was no difference in plasma fluoride levels between those working in the Søderberg and prebake departments.

\section{Discussion}

Plasma fluoride levels were found to be positively associated with bronchial responsiveness. A positive relation between plasma fluoride levels and total fluoride in the environment was also established.

This result could be biased by the large number of dropouts. We therefore investigated this possibility in three ways: (1) by plotting the individual least squares regression slopes against the number of follow ups and estimating the relationship between the $\ln (\mathrm{DRS}),(2)$ the number of follow up visits during the complete study period, and (3) the plasma fluoride levels in a subset of the follow up visits. None of these analyses indicated any association between the outcome and the number of follow up visits. Since a confounder must be associated with the outcome as well as the exposure under study, ${ }^{27}$ we believe that the estimated association between bronchial responsiveness and plasma levels of fluoride is not distorted by the large number of dropouts.

In a cross-sectional study of bronchial responsiveness at the same plant in 1988 we found no association between bronchial responsiveness and occupational exposure to particulates or fluoride in the environment. ${ }^{28}$ This negative result could be explained by a selection bias as subjects with increased bronchial responsiveness are more likely to leave jobs with greater exposure than subjects with normal bronchial responsiveness. In a longitudinal design the subjects are their own controls and this type of selection bias can be virtually eliminated. ${ }^{29}$

Although a positive association between bronchial responsiveness and plasma fluoride levels was found, some caution is needed in the interpretation of the result. In this context plasma fluoride levels are merely an index of occupational exposure - that is, the causative agent could be a non-fluoride containing agent such as sulphur dioxide or other components of the potroom atmosphere. Nevertheless, the finding that plasma fluoride levels were positively correlated with total fluoride levels indicates that an agent containing fluoride may be more likely to be the causative agent. A 
similar finding is also reported for respiratory symptoms. ${ }^{1028}$

The adequacy of the GEE method could be questioned. We found, however, a large overlap between the estimates supported by the univariate GEE analysis and the mean estimate obtained from the least squares regression. The GEE method resulted in wider confidence intervals than the least squares regression, as expected. ${ }^{20}$

Since bronchial responsiveness decreased during the follow up period, the estimated association between bronchial responsiveness and plasma fluoride levels may be due to a "regression toward the mean" effect ${ }^{24}$ as the subjects were included on the basis of the presence of respiratory symptoms. Although this possibility cannot be ruled out, we believe that the inclusion of follow up time adjusts for the regression effect.

Ehrnebo and Ekstrand studied the relation between exposure to fluoride and plasma fluoride levels in aluminium potroom workers ${ }^{25}$ and found, on average, a doubling of the plasma fluoride levels from the preshift value. The plasma fluoride level is therefore a good indicator of exposure to fluoride on the day of the bronchial challenge. However, total exposure to fluoride (estimated from the routine surveillance) could be regarded as an estimate of the mean background level of fluoride. From these considerations and the observation that bronchial responsiveness was mainly determined by plasma fluoride levels, it seems likely that bronchial responsiveness can increase rapidly following acute, high exposure to fluoride (the workers had been exposed 4-6 hours before the bronchial challenge). In a previous report we were unable to find any association between bronchial responsiveness and duration of exposure. ${ }^{28}$ Previous exposure was not therefore considered as a covariate in these analyses.

It is generally accepted that airway inflammation can be induced by sensitisers ${ }^{30}$ or by irritants such as chlorine, acid, sulphur dioxide, after single accidental high exposure. ${ }^{31}$ Whether airway inflammation can be induced by repeated exposure to low levels of irritants is controversial. Hjortsberg and coworkers reported late asthmatic reaction with potassium aluminium tetrafluoride. ${ }^{32}$ Gylseth and coworkers demonstrated fibres thinner than $0.1 \mu \mathrm{m}$ in diameter and shorter than $5 \mu \mathrm{m}$ in the potroom atmosphere. ${ }^{33}$ These were identified as sodium aluminium tetrafluoride $\left(\mathrm{NaAlF}_{4}\right)$ which is very similar to potassium aluminium tetrafluoride. It is possible that $\mathrm{NaAlF}_{4}$ can act as a hapten, and this hypothesis should be tested by the specific provocation of workers with potroom asthma using $\mathrm{NaAlF}_{4}$.

Working in the Søderberg potroom was associated with an increase in bronchial responsiveness compared with the prebake potroom. Since the atmospheric exposure to fluoride was lower in the Søderberg than in the prebake potrooms, this finding may be caused by a selection effect. None of the subjects was exposed in both kinds of potrooms, so the advantage of a longitudinal design is not ap- plicable when comparing the effects of exposure in the prebake and Søderberg potrooms.

A weak, although significant, negative association between bronchial responsiveness and exposure to total particulates was found. It is difficult to explain this relationship in terms of the misclassification of exposure as this should bias the estimate towards the zero effect, ${ }^{34}$ provided that the classification of particulate exposure was independent of the outcome (bronchial responsiveness). It is possible that the workers in the most dusty environment were more likely to wear respiratory safety masks causing a preventive effect on particulate exposure. However, we have no data on this. Alternatively, the association might arise as a result of the colinearity between exposure to total particulates and total fluoride as outlined above. Finally, in a previous cross-sectional study we found a slight negative relation between exposure to total particulates and respiratory symptoms ${ }^{28}$ so that a protective effect by the dust - for example, alumina - on the airways cannot be ruled out.

We also found a positive relation between plasma levels of fluoride and total fluoride exposure, but not with exposure to total particulates. In a study of aluminium potroom workers Ehrnebo and Ekstrand found a positive relation between fluoride exposure measured by personal samplers and plasma fluoride levels. ${ }^{25}$ In their study the blood samples and the environmental measurements were taken from the same subjects. In our study estimates of environmental exposure were obtained from the routine surveillance of the potroom environment. Nevertheless, it appears that there is a good agreement between the results of these two studies. Some cautions must, however, be taken into account in our study because of colinearity between atmospheric levels of fluoride and particulates.

In conclusion, a positive association between bronchial responsiveness and plasma fluoride levels was found in subjects reporting workrelated asthmatic symptoms. It is possible that this effect is caused by fluoride exposure in the environment, although confounding by another agent cannot be ruled out.

\section{Appendix}

Let $\mathrm{DRS}_{x}$ correspond to the dose-response slope at a level $x$ of a covariate $\mathrm{X}$, and $\mathrm{DRS}_{x+\Delta x}$ to the dose-response slope after increasing $\mathrm{X}$ by the amount of $\Delta x$. The estimated change in DRS from the GEE analysis is then given by:

$$
\begin{aligned}
& \ln \left(\mathrm{DRS}_{x+\Delta x}\right)-\ln \left(\mathrm{DRS}_{x}\right)= \\
& \beta \times(x+\Delta x)-\beta \times x \\
& \ln \left(\mathrm{DRS}_{x+\Delta x} / \mathrm{DRS}_{x}\right)=\beta \times \Delta x \\
& \mathrm{DRS}_{x+\Delta x} / \mathrm{DRS}_{x}=\exp (\beta \times \Delta x) \\
& 95 \% \mathrm{CI} \text { for } \mathrm{DRS}_{x+\Delta x} / \mathrm{DRS}_{x}: \\
& \exp (\beta \times \Delta x \pm 1.96 \times \mathrm{SE} \times \Delta x)
\end{aligned}
$$

If DRS increases as $x$ increases, the ratio $\mathrm{DRS}_{x+\Delta x} / \mathrm{DRS}_{x}>1$ and $\mathrm{DRS}_{x+\Delta x} / \mathrm{DRS}_{x}$ is $<1$ if DRS decreases as $x$ increases. 
The authors thank the plant physicians for their valuable comments on the manuscript. We also wish to thank Mrs Eva Kari Foosnæs and Mrs Kristin Moen for their technical assistance, as well as Mrs Grete Botten, Mr Helge Kjuus, Mr Peter Laake, Mr Dag Malterud and Mr Eirik Nordheim for their comments and constructive criticism.

The study was supported by grants from the Norwegian Work and Environment Fund, the Norwegian Society for Allergy and Immunopathology, and the Swedish Medical Research Council (Pno 9439).

1 Enarson DA, Vedal S, Schulzer M, Dybuncio A, Chan Yeung M. Asthma, asthmalike symptoms, chronic bronchitis, and the degree of bronchial hyperresponsiveness in epidemiologic surveys. Am Rev Respir Dis 1987;136:613-7.

2 Josephs LK, Gregg I, Mullee MA, Holgate ST. Nonspecific bronchial reactivity and its relationship to the clinical expression of asthma. Am Rev Respir Dis 1989;140:350-7.

3 Søyseth V, Kongerud J, Boe J. Determinants of bronchial responsiveness in aluminium potroom workers. A lon-
gitudinal study. Eur Respir $\mathcal{f} 1992 ; 5$ (Supplement 15):406.

4 Mapp CE, Dal Vecchio L, Boschetto P, De Marzo N, Fabbri LM. Toluene diisocyanate-induced asthma without airway hyperresponsiveness. Eur $\mathcal{F}$ Respir Dis 1986;68:89-95.

5 Burge PS. Non-specific hyper-reactivity in workers exposed to toluene di-isocyanate, diphenyl methane di-isocyanat and colophony. Eur $\mathcal{F}$ Respir Dis 1982;63:91-100.

6 Durham SR, Hawkins R, Newman Taylor AJ. The temporal relationship between increases in airway responsiveness to histamine and late asthmatic responses induced by occupational agents. F Allengy Clin Immunol 1987;79:398406.

7 Fabbri LM, Boschetto P, Zocca E, Milani G, Pivivrotto F Plebani $\mathrm{M}$, et al. Bronchoalveolar neutrophilia during late asthmatic reactions induced by toluene diisocyanate. $\mathrm{Am}$ asthmatic reactions induced by
Rev Respir Dis 1987;136:36-42.

8 Cockcroft DW. Airway hyperresponsiveness and late asthmatic responses. Chest 1988;94:178-80.

9 Frostad EW. Fluorine intoxication in Norwegian aluminium plant workers. Tidsskr Nor Laegefor 1936;56:79 (in Norwegian)

10 Kongerud J, Samuelsen SO. A longitudinal study of respiratory symptoms in aluminium potroom workers. $A m$ Rev Respir Dis 1991;144:10-6.

11 Abramson MJ, Wlodarczyk JH, Saunders NA, Hensley MJ. Does aluminium smelting cause lung disease? $\mathrm{Am}$ Rev Respir Dis 1989;139:1042-57.

12 O'Donnel TV, Welford B, Coleman ED. Potroom asthma: New Zealand experience and follow-up. Am $\mathcal{F}$ Ind Med 1989;15:43-9.

13 Søyseth V, Kongerud J, Boe J, Fonneland T. Bronchial responsiveness and work-related asthma in aluminium potroom workers. Eur Respir 7 1992:5:829-33.

14 Kongerud J, Aalen OO, Vale JR. Questionnaire reliability and validity for aluminium potroom workers. Scand Work Environ Health 1989;15:364-70.
15 Gulsvik A. Obstructive lung disease in an urban population (dissertation). Rikshospitalet, University Hospital, Oslo, 1979.

16 Cockcroft DW, Killian DN, Mellon JJA, Hargeave FE. Bronchial reactivity to inhaled histamine: a method and a clinical survey. Clin Allergy 1977;7:235-43.

17 a clinical survey. Clin Allergy 1977;7:235-43. in blood plasma and saliva. Calcif Tiss Res 1977;23:225-8.

18 Kongerud J, Grønnesby JK, Magnus P. Respiratory symptoms and lung function of aluminium potroom workers Scand $\mathcal{f}$ Work Environ Health 1990;16:270-7.

19 O'Connor G, Sparrow D, Taylor D, Segal M, Weiss S. Analysis of dose-response curves to methacholine. Am Rev Respir Dis 1987;136:1412-7.

20 Zeger S, Liang K. Longitudinal data analysis for discrete and continuous outcome. Biometrics 1986;42:121-30.

21 Gebski V, Leung O, McNeil D, Lunn D. SPIDA user's manual. Eastwood, NSW, Australia: Statistical Computing Laboratory, 1992.

22 Kongerud J, Søyseth V. Methacholine responsiveness, respiratory symptoms and pulmonary function in aluminium potroom workers. Eur Respir $¥ 1991 ; 4: 159-66$.

23 Miller MR, Pincock AP. Predicted values: how should we use them? Thorax 1988;43:265-7.

24 Senn SJ, Brown RA. Estimating treatment effects in clinical trials subject to regression to the mean. Biometrics 1985 41:555-60.

25 Ehrnebo M, Ekstrand J. Occupational fluoride exposure and plasma fluoride levels in man. Int Arch Occup Envin Health 1986;58:179-90.

26 Hosmer DW, Lemeshow S. Applied logistic regression. New York: Wiley, 1989:82-7.

27 Kleinbaum DG, Kupper L, Morgenstern H. In: Epidemiological research. Principles and quantitative methods. New York: Van Nostrand Reinhold, 1982:252-3.

28 Søyseth V, Kongerud J. Prevalence of respiratory disorders among aluminium potroom workers in relation to exposure to fluoride. $B r \exists$ Ind Med 1992;49:125-30.

29 Zeger SL, Liang K-Y. An overview of methods for the analysis of longitudinal data. Stat Med 1992;11:1825-39.

30 Holgate ST, Roche W, Djukanovic R, Wilson J, Britten K Howarth P. The need for a pathological classification of asthma. Eur Respir f 1991;4(Suppl 13):113-22.

31 Tarlo SM, Broder I. Irritant-induced occupational asthma. Chest 1989;96:297-300.

32 Hjortsberg U, Nise G, Ørbeck P, Søes-Petersen U, Arborelius M. Bronchial asthma due to exposure to potassium aluminium tetrafluoride. Scand $\mathcal{f}$ Work Environ Health 1986;12:223 (letter to the editor).

33 Gylseth B, Bigrseth O, Dugstad Ø, Giannes J Occurrence of fibrous sodium aluminiumtetrafluoride particles in potrooms of the primary aluminium industry. Scand $\mathcal{f}$ Work rooms of the primary aluminium

34 Kleinbaum DG, Kupper L, Morgenstern H. In: Epidemiological research. Principles and quantitative methods. New York: Van Nostrand Reinhold, 1982:220-41. 